\title{
TÜRKÇELEŞME ve MEHMET EMIN YURDAKUL'UN TÜRKÇE ŞiiRLERi
}

\section{Etymological Translation into Turkish and Mehmet Emin Yurdakul's Turkish Poetry}

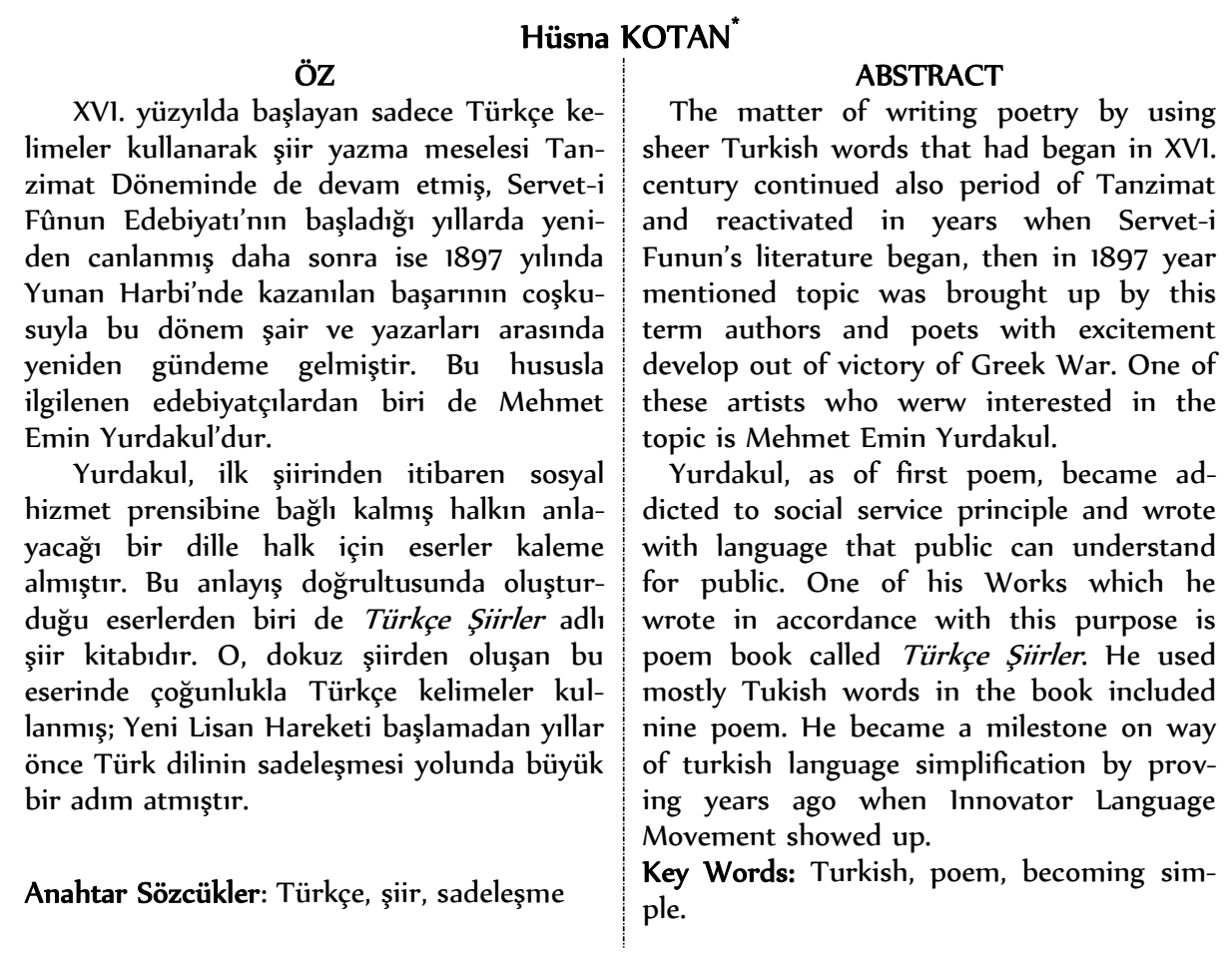

\section{Giriş}

Türklerin cihangirlik duyguları ve X. yüzyılda ìslamiyet'i kabul etmeleri ile dilimize birçok yabancı sözcük girmeye başlamıştır. Bu durumun sonucunda Arapça ve Farsça kelimeleri kullanma eğiliminde olan şairler Türkçenin fakirliği ve yetersizliğinden şikâyet ederek Türkçe kelimeleri terk edip yabancı kelimeler kullanmışlardır. Dolayısıyla Türk dili bu süre içerisinde olumsuz yönde etkilenmiș ve dilde yabancılaşma bașlamıştır. Bu yabancılaşmaya karşı bir önlem alınması gerektiği düşünülmüş, Türkçenin, Arapça ve Farsçadan daha zengin olduğunun ispat edilme gerekliliği ortaya çıkmıştır.

\footnotetext{
*Atatürk Üniversitesi Edebiyat Fakültesi Türk Dili ve Edebiyatı Bölümü. husna@atauni.edu.tr
} 
Aslında Türkçenin zenginliğine Xl. yüzyılda Kâşgarlı Mahmud'un yazdığı Divânu Lugâti't-Türk adlı eser ile dikkat çekilmiş ve Türkçe gereği gibi tanıtılmıştır (Levend 1949: 11). Daha sonra ise XV. yüzyılda Aydınlı Visali, XVl. yüzyılda Tatavlı Mahremi ile Edirneli Nizami, XVIIl. yüzyılda ise Nedim gibi şairler sade bir dil kullanmaya çalışmışlardır. XIX. yüzyıla gelindiğinde ise sadeleşme akımını devam ettiren Esad Mehmed Efendi'yi (Levend 1949: 95) Tanzimatçllardan Şinasi, Ali Suavi, Ahmet Mithat Efendi, Şemseddin Sami, Ahmet Vefik Paşa, Ahmed Cevdet Paşa, Süleyman Paşa, Muallim Naci gibi belli başlı fikir ve kalem sahipleri takip etmişlerdir (Öksüz 2004: 18-28).

"Sanat sanat içindir" anlayışını ilke edinen Servet-i Fünuncular ise daha önce Türkçeyi sadeleştirme adına yapılan çalışmaların aksine, duygu ve düşüncelerini tüm incelikleriyle ifade edebilecekleri bir dil oluşturma çabasına girişmişler. Böylelikle Fransız edebiyatına yönelen bu dönem şair ve yazarları özellikle Parnasizm ve Sembolizm akımlarının etkisiyle Fransızca yeni tamlamalar kullanmışlar hatta sözlüklerde hiç bulunmayan Arapça ve Farsça kelimelere eserlerinde yer vererek konuşma dilinden uzak girift ve anlaşılmaz bir dil ve üslup meydana getirmişlerdir. Bu yeni dilin en dikkate değer örneklerini nesirde Halid Ziya Uşaklıgil, nazımda Tevfik Fikret vermiştir (Akyüz 1995: 9091).

Bunun sonucunda Servet-i Fünun döneminde yavaşlamaya başlayan dilde sadeleşme hareketi Meşrutiyet döneminde büyük bir hız kazanmıştır. Özellikle 19ı1'de Selânik'te Genç Kalemler dergisinin ikinci cildinin birinci sayısında Ömer Seyfettin tarafindan yazılan ve imza yerinde büyük bir soru işareti bulunan Yeni Lisan başlıklı yazı millî bir uyanışın ilk belirtilerini oluşturmuş Yeni Lisan Hareketini başlatmıştır (Levend 1949: 322). Bu hareket ile Ali Canip Yöntem, Ömer Seyfettin ve Ziya Gökalp Türk dilinin sadeleşmesi ve millî değerlerin korunması yolunda önemli adımlar atmışlardır (Öksüz 2004: 133). Bu adımlardan biri de Türkçe şiirler yazma konusudur. Sadece Türkçe kelimeler kullanarak şiir yazma hususunda, 1897'de Selanik'te Asır Gazetesi'nde çıkan ve büyük bir inancın heyecanını taşıyan "Ben Türküm!, Dinim cinsim uludur,/ Sinem, özüm ateş ile doludur.” manzumesi ile Mehmet Emin Yurdakul edebiyat dünyasında yepyeni bir ses olarak karşılanmıştır.

Yurdakul, bu eserinden iki yıl sonra Maarif Nezaret-i Celilesi (Milli Eğitim Bakanlı̆̆ı) nin izniyle Türkçenin sadeleşme sürecinde önemli bir eser olan Türkçe Şiirler 'i yayımlamıştır (Oğuzkan 1953: 4). Bu eser “Biz Nasıl Şiir Isteriz?, Anadolu'dan Bir Ses Yâhud Cenge Giderken, Yunan Sınırını Geçerken, Tırhala Kal'ası'na Bayrak Diktikten Sonra, Şehid Yâhud Osman'ın Yüreği, Yetim Çocuk Yâhud Ahmed'in Kaygusu, Âh Analık Yâhud Zeyneb'in Duâsı, Kur'ân-ı Kerim, Güzellik ve lyilik Karşısında”' olmak üzere toplam dokuz şiirden oluşmaktadır (Tansel 1969: 21-35).

Mehmet Emin' nin bu eseri şiir tekniği ve sanat bakımından üstün bir değer taşımasa da; şairin halkın hayatından aldığı konuları, halkın anlayıp zevk alabileceği bir dille

'Fevziye Abdullah Tansel, Mehmet Emin Yurdakul'un Eserleri- I Şiirler, Türk Tarih Kurumu Yayınlarından Seri: 11- Sayı: 24, TTK. Basımevi, Ankara, 1969, ss. 21-35. 
işlemesi bakımından büyük bir öneme sahiptir. Zaten Mehmet Emin'in sanatının gayesi ideal güzele ulaşmak değil, milli bir fayda sağlamak olmuştur.

Yurdakul, bu gaye doğrultusunda ilk şiirinden başlayarak sosyal hizmete yönelik bir sanat anlayışına bağlanmış ve bu anlayıştan sonuna kadar hiçbir şekilde ayrılmamıştır. Şiirlerinde genel olarak çok açık bir halkçılık ve milliyetçilik göze çarpmaktadır. Öyle ki şair kendi özel hayatına dair hiçbir hususu ve özel isteğini şiire aks ettirmemiş eserlerinde tabiat tasvirlerine bile yer vermeyerek yalnızca sosyal fayda prensibine bağlı kalmıştır (Akyüz 1995:135).

Edebiyat yaşantısı boyunca eserlerinde hem içerik hem de yapı bakımından saf ve duru bir Türkçe duyarlılı̆̆ını yansıtmayı başaran Yurdakul'un Türkçe Şiirler adlı eserindeki şiirler söz varlı̆ı bakımından incelenmiş ve onun şiirlerinde Türkçe ve yabancı kelimelerin nasıl ve hangi sıklıkta kullanıldığı ortaya konulmuştur.

Türkçe Şiirler' de kullanılan kelimeler şöyle gruplandırılabilir:

1. Türkçe Kökenli Kelimeler

2. Yabancı Kökenli Kelimeler

3. Yabancı Kelime ve Türkçe Eklerle Oluşturulan Kelimeler

\section{Türkçe Kökenli Kelimeler}

Yurdakul'un Türkçe Şiirler adlı eserinde sözcükler tekrarsız olarak ele alındığında toplam dört yüz elli dokuz sözcügün kullanıldığı tespit edilmiştir. Bu kelimelerden üç yüz elli iki tanesi Türkçedir. Bu sözcüklerin şsiirlerdeki kullanım oranı yüzde yetmiş yedi'dir. Bunların tür bakımından dağııımı şöyledir:

a. İsimler: Türkçe Şïrler'de iki yüz kırık üç isim soylu sözcük yer almaktadır. Bu kelimeler isim, sıfat, zarf, zamir, edat, bağlaç ve ünlem gibi görevlerde kullanılmıştır. İsim olarak kullanılan sözcüklerin sayısı yüz yirmi'dir. Bunların toplam sözcükler içerisinde kullanım oranı yüzde yirmi altı'dır. Bu sözcükler şiirde özel, yalın, türemiş ve birleşik isimler; ikilemeler, yansıma sözcükler şeklinde kullanılmışır.

Özel İsimler: Şiirlerde beş Türkçe özel isim yer almaktadır. Örnekleri şöyledir:

Hangi Türk'tür mescidine çanlı kule kurdurur?

Milletimiz köle olmaz; böyle günde kim durur?

Biz Türkler'iz; Kızılırmak olur böyle taşarız!

(Yunan Sınırını Geçerken)

Köroğlu ne? Anadolu dağlarında görünen,

Hep evleri, yapıları çamurlara bürünen,

Köycüklerde, rencberlerin yurtlarında okunur:

(Biz Nasıl Şiir isteriz?)

Yalın İsimler: Şiirlerde yetmiş dört yalın isim kullanılmıştır. Bunlarla ilgili birkaç örnek şöyle gösterilebilir:

Yüce dağlar başlarına çıkalım;

Ormanlara, ovalara bakalım; 
(Güzellik ve lyilik Karşısında)

\section{Türemiş İsimler}

a.İsimden Türemiş İsimler: Şiirlerde on bir sözcük isimden türemiş isim olarak kullanılmıştır. Bu sözcüklere şu şekilde örnek gösterebiliriz:

Ey iyilik, ey dünyânın, insanlığın ümidi!

Seni herkes bir parçacık dinleseydi, görseydi;

(Güzellik ve lyilik Karşısında)

Ey parlak ay! Işığın saç, yolcuların gözüne;

O yerde ki kötü gece gizlemiştir mezarım.

(Şehid Yahud Osman'ın Yüreği)

b.Fiilden Türemiş İsimler: Şiirlerde yirmi bir sözcük fiilden türemiş isim olarak kullanılmıştır. Örnekleri şöyledir:

Çıplak dağlar yeşilleten, viran köyler şenleten

Bu bilgidir: Ululuğun yapıların kurduran;

(Kur'an-1 Kerim)

Ey Türk-ili, ey vatan! Sen her bir yerden ulu'sun!

Eski, yeni, tatl, yanı sesler ile dolusun!

Sevgi, gençlik, istek, sağlık fedâ olsun yolunda!..

(Şehid Yahud Osman'ın Yüreği)

Birleşik İsimler: Şiirlerde dört Türkçe birleşik isim yer almaktadır. Örneğin:

Seni kuşlar söylesin!

Gecekuşu viran yerler taşlarında öterken

(Güzellik ve íyilik Karşısında)

Gökyüzünden kevkebler,

Işıkların bize doğru saçarlar;

(Güzellik ve Iyilik Karşısında)

Ak gömlekle gözyaşımı silerim.

Kara taşla bıçağımı bilerim.

(Anadoludan Bir Ses Yahud Cenge Giderken)

Yansıma İsimler: Şiirlerde dört yansıma sözcük kullanılmıştır. Şiirden bazı örnekleri şöyle gösterebiliriz:

Ey parlak ay! Işı̆ğın saç, yolcuların gözüne;

O yerde ki kötü gece gizlemiştir mezarım.

(Şehid Yâhud Osman'ın Yüreği)

Yüreğinin özleriçün çarpındığın duysunlar; 
Bu çarpınt, bu ses nedir; neler diyor? Bilsinler.

(Biz Nasıl Şiir İsteriz?)

Ey kardeşler!... Ses gelmiyor; âh kimseden ümid yok;

Kar yağıyor.. Firtına var.. Yolu çı̆lar almıştır.

(Âh Analık Yâhud Zeyneb'in Duâsı)

ikilemeler: Şiirlerde isim görevinde bir ikileme kullanılmıştır. Örneğin:

Üstü başı eski püskü, yalın ayak yavrucuk.

Gözlerini yola dikmiş; birisini bekliyor

(Yetim Çocuk Yâhud Ahmed'in Kaygusu)

Şiirde sıfat olarak kullanılan sözcüklerin sayısı yetmiş dört'tür. Bu sözcüklerin toplam kelimeler içerisindeki kullanım oranı ise yüzde on altı'dır. Şiirde yalın halde kullanılan sıfatların yanı sıra isim ve fiil kökü ile de oluşturulan sıfatlar dikkat çekmektedir. Ayrıca bazı birleşik isimler, ikilemeler, yansıma sözcükler de sıfat görevinde kullanılmıştır. Bu sıfatlar şöyledir:

Yalın Sıfatlar: Şiirlerde otuz iki yalın sıfat yer almaktadır. Bunlardan bazıları belirtme sıfatı olarak kullanılırken bazıları niteleme sıfatı olarak kullanılmıştır. Örnekleri şöyledir:

Bir şiir ki şehidlerin al kanıyla yazılmış;

Bir kılıç ki bir kitabın alt yanına asılmış;

Bir altundan heykeldir ki bir odaya konulmuş.

(Biz Nasıl Şiir İsteriz?)

Türemiş Sıfatlar:

a.İsimden Türemiş Sıfatlar: İsimden isim yapma ekiyle oluşturulmuş sözcüklerden yedisi niteleme sıfatı görevinde kullanılmıştır. Bazı örnekleri şöyledir:

Kırda köylü genç kızlar,

Etek etek çiçekleri tutarlar;

$O$ dikenli yolumuza atarlar.

(Güzellik ve lyilik Karşısında)

Bir kitap ki ya bir yetim keçisini çaldırtır;

Ya bir çiftçi çocuğunu ıssız dağa kaldırtır;

(Biz Nasıl Şiir İsteriz?)

b.Fiilden Türemiş Sıfatlar: Fiilden isim yapma ekiyle oluşturulmuş sözcüklerden otuzu niteleme sıfatı görevinde kullanılmıştır. Bu sözcükler şiirde şu şekilde görülmektedir:

Bu Kitâb'tır: Yürekleri iyilikle besleyen;

"El bağına girme!" diyen, dost yarasın bağlatan.

(Kur'an-1 Kerim) 
Birleşik Sıfatlar: Şiirlerde iki birleşik kelime sıfat görevinde kullanılmıştır. Örneğin:

Viran köyü bir yayladan ayıran ıssız dağın,

Yeşil, penbe gölgelere hasret çeken ırmağın

Eteğinde, birkaç kırık fidancı̆̆ın yanında;

(Yetim Çocuk Yahud Ahmed'in Kaygusu)

Hangi Türk'tür mescidine çanlı kule kurdurur?

Milletimiz köle olmaz; böyle günde kim durur?

(Yunan Sınırını Geçerken)

Sıfat Görevinde Kullanılan Yansıma Sözcükler ve ikilemeler: Şiirlerde iki ikileme, bir yansıma sözcük ise sıfat görevinde kullanılmıştır. Örnekleri şöyledir:

Bu bilgidir: Ululuğun yapıların kurduran;

Çıplak dağlar yeşilleten, viran köyler şenleten.

(Kur'an-1 Kerim)

Kırda köylü genç kızlar,

Etek etek çiçekleri tutarlar;

(Güzellik ve lyilik Karşısında)

On yaşında boynu bükük, bağrı yanık bir çocuk,

Üstü başı eski püskü, yalın ayak yavrucuk.

(Yetim Çocuk Yahud Ahmed'in Kaygusu)

Şiirlerde on dokuz sözcük zarf görevinde kullanılmıştır. Zarfların toplam sözcükler içerisindeki kullanım oranı yüzde üç’tür. Şiirde yalın, birleşik sözcükler ve bazı ikilemeler zarf görevinde kullanılmıştır. Şiirde kullanılan zarflar şöyledir:

Yalın Zarflar: Şiirlerde on üç sözcük yalın zarf olarak kullanılmıştır. Örnekleri şöyle gösterebiliriz:

Uzaklardan yola doğru bir karaltı görünce,

Her genç rencber tarlasından köycüğüne dönünce,

“işte odur, odur!" diye sevinerek koşuyor.

(Yetim Çocuk Yahud Ahmed'in Kaygusu)

En güzel yüz bize çirkin; biz severiz Türk yüzü.

En iyi öz bize fenâ; biz isteriz Türk özü.

(Yunan Sınırını Geçerken)

Birleşik Zarflar: Şiirlerde üç kelime birleşik zarf görevinde kullanılmıştır. Örneğin:

$O$ ninnidir: Yine bugün bize söyler Sögüd'ü.

$O$ dillerdir: Yine bugün bize verir ögüüü.

(Yunan Sınırını Geçerken)

Milletimiz köle olmaz; böyle günde kim durur? 
Biz Türkler'iz; Kızılırmak olur böyle taşarız!

(Güzellik ve lyilik Karşısında)

Zarf Görevinde Kullanılan îkilemeler: Şiirlerde üç ikileme zarf görevinde kullanılmıştır. Bazıları şöyledir:

Sakladığı elmaları samanlıktan çıkarıp

Gögüscüğü üzerinde sıkı sıkı tutuyor.

(Yetim Çocuk Yahud Ahmed'in Kaygusu)

Parlak güneş ilk ışığın mâvi göle serperken,

Yavaş yavaş ikimiz,

Yüce dağlar başlarına çıkalım;

(Güzellik ve lyilik Karşısında)

Şiirde on iki kelime zamir olarak kullanılmıştır. Bu sözcük türünün kullanım oranı yüzde üç'tür. Şiirlerde yalın ve türemiş zamirler kullanılmıştır.

Yalın Zamirler: Şiirlerde on sözcük yalın zamir kullanılmıştır. Örneklerini şöyle gösterebiliriz:

Ben bir Türk'üm dinim, cinsim uludur,

Sinem, özüm ateş ile doludur,

(Anadoludan Bir Ses Yahud Cenge Giderken)

Türemiş Zamirler: Şiirlerde iki kelime türemiş zamir kullanılmıştır. Bu zamirler şunlardır:

Ey kardeşler!... Ses gelmiyor; âh kimseden ümid yok;

Kar yağıyor.. Fırtına var.. Yolu çı̆̆lar almıştır.

(Âh Analık Yâhud Zeyneb'in Duâsı)

Üstü başı eski püskü, yalın ayak yavrucuk.

Gözlerini yola dikmiş; birisini bekliyor.

(Yetim Çocuk Yahud Ahmed'in Kaygusu)

Şiirlerde on üç sözcük edat, bağlaç ve ünlem görevinde kullanılmıştır. Bu sözcüklerin kullanım oranı yüzde üç'tür. Edatlardan bazıları isim, zamir ve zarflarla birlikte kullanılmıştır.

Edat, Bağlaç ve Ünlemler: Bu sözcüklerin örnekleri şöyledir:

"Köyümüze askerliği bitirerek dönen çok;

“Çiçek-ayı'nda gitmişti; bu günedek haber yok;

"Babacığım nice olmuş? Yolculardan sordun mu?"

(Yetim Çocuk Yâhud Ahmed'in Kaygusu)

Başlarını açık, beyaz sinesine koysunlar; 
Yüreğinin özleriçün çarpındığın duysunlar;

Bu çarpıntı, bu ses nedir; neler diyor? Bilsinler.

(Biz Nasıl Şiir İsteriz?)

$O$ ninnidir: Yine bugün bize söyler Söğüd'ü.

$O$ dillerdir: Yine bugün bize verir ögüüü.

(Yunan Sınırını Geçerken)

Işste bu gün yine yaktık; eski, sönük çerağı.

Bu kal'aya biz de diktik ulu devlet bayrağı.

(Tırhala Kal'ası'na Bayrak diktikten Sonra)

Ey soğuk kar!... Söyletmiyor; oh, yüzümü yakıyor;

Yol belirsiz.. Bilmiyorum.. Uçurum mu şu düz yer.

(Âh Analık Yâhud Zeyneb'in Duâsı)

Bunların dışında şiirlerde beş sözcük iki görevde kullanılmıştır. Örneğin çok, iyi ve nice kelimeleri sıfat ve zarf görevinde; gün, isim ve zarf görevinde; yavru ise isim ve sıfat görevinde kullanılmıştır.

b.Fiiller: Türkçe Şiirler'de fiil soylu yüz altı sözcük kullanılmıştır. Bu sözcüklerin kullanım oranı yüzde yirmi dört'tür. Şiirlerde yalın, türemiş ve birleşik yapıda kullanılan fiiller görülmektedir.

Yalın fiiller: Şiirlerde seksen kelime yalın fiil kullanılmıştır. Örnekleri şöyledir:

Yetimleri, yoksulları soralım;

Acıyalım, ağlayalım, okşayalım; sevelim.

(Güzellik ve lyilik Karşısında)

\section{Türemiş Fiiller:}

a.Isimden türemiş fiiller: Şiirlerde dört sözcük isimden türemiş fiil olarak kullanılmıştır. Örneğin:

Yiğit, arslan babamı pek garibsedim, özledim;

Gün karardı; şimdiyedek onun yolun gözledim

(Yetim Çocuk Yahud Ahmed'in Kaygusu)

b. Fiilden Türemiş Fiiller: Şiirlerde yirmi iki sözcük fiilden türemiş fiil olarak kullanılmıştır. Örnekleri şöyledir:

Bir kitap ki ya bir yetim keçisini çaldırtır;

Ya bir çiftçi çocuğunu ıssız dağa kaldırtır;

(Biz Nasıl Şiir İsteriz?)

Birleşik Fiiller: Bir isim ve bir yardımcı fiilin birleşmesi ile oluşan fiillerdir. Şiirlerde ise Türkçe bir isim ve Türkçe bir yardımcı fiilin birleşmesi sonucu oluşan dokuz birleşik 
fiil kullanılmıştır. Bunlardan üçü ise sıfat-fiil eki aldığı için sıfat görevinde kullanılmıştır. Örnekleri şöyledir:

Senin için dolaşırım, tepeleri, belleri.

isterim ki bana herşey yol versin;

(Güzellik ve liyilik Karşısında)

Bu Kitâb'tır: Her kişiye benlik veren, yol açan;

insanlığın sergisine armağanlar asdıran.

(Kur'an-1 Kerim)

\section{Yabancı Kökenli Sözcükler:}

Şiirlerde toplam seksen sekiz tane yabancı kökenli sözcük kullanılmıştır. Bu sözcüklerin kullanım oranı yüzde on dokuz'dur. Şiirlerde köken itibariyle Arapça, Farsça, Yunanca, İtalyanca ve Moğolca sözcükler bulunmaktadır. Çoğunlukla isim görevinde kullanılan bu kelimelerin hiçbiri fiil olarak kullanılmamıştır.

Arapça İsimler: Şiirlerde kırk bir Arapça kelime yer almaktadır. Bunlardan otuz dördü isim görevinde, üçü sıfat, biri zarf, biri de zamir görevinde kullanılırken iki sözcük de hem isim hem de sıfat görevinde kullanılmıştır. Örnekleri şöyledir:

Bir şiir ki şsehidlerin al kanıyla yazılmış;

Bir kılıç ki bir kitabın alt yanına asılmış;

Bir altundan heykeldir ki bir odaya konulmuş.

(Biz Nasıl Şiir İsteriz?)

En iyi öz bize fenâ; biz isteriz Türk özü.

Milletimiz alkışlarız; anıldıkça Türk sözü.

(Yunan Sınırını Geçerken)

Fâtih nedir? Istanbul'un surlarının altında,

Karadeniz-boğazı'nda, Hisarlar'in sırtında,

Gayet güzel düşünülmüşs, gāyet iyi duyulmuş:

(Biz Nasıl Şiir İsteriz?)

Özel isimler: Şiirlerde kullanılan Arapça isimlerden altısı özel isim olarak kullanılmıştır. Örneğin:

Ey kardaşlar! Şu küçücük armaganım atmayın;

Bir goncadır: Muhammed'in gül bağından derildi.

(Kur'an-1 Kerim)

Farsça İsimler: Şiirlerde otuz yedi Farsça kelime yer almaktadır. Bunlardan yirmi biri isim, dokuzu sıfat, biri zarf, biri zamir, beşi ise edat ve bağlaç görevinde kullanılmıştır. Örnekleri şöyledir:

Biz Türkler'iz; düşmanlara yalın kılıç koşarız!

Hangi Türk'tür gerdenine urgan, kement urdurur?

(Yunan Sınırını Geçerken) 
$48^{*}$ TAED 49

Dağlarında tâze otlar, penbe güller biterken.

Ey çobanlar! Beni anın, coşkun sular başında;

(Şehid Yahud Osman'ın Yüreği)

Ey iyilik, ey dünyânın, insanlı̆̆ın ümudi!

Seni herkes bir parçacık dinleseydi, görseydi;

(Güzellik ve liyilik Karşısında)

Seni her yer gizlemeyip göstersin.

Eğer birgün gözlerim,

Görmez ise şu korudan geçerken,

(Güzellik ve lyilik Karşısında)

Yunanca İsimler: Şiirlerde dokuz Yunanca isim kullanılmıştır. Bunlardan dördü özel isimdir. Örnekleri şöyledir:

Sakın, bunu yapma çiçek demetine katmayın;

Bu şey size özünüzü açmak için verildi.

(Kur'an-1 Kerim)

Kör oğlu ne? Anadolu dağlarında görünen,

Hep evleri, yapıları çamurlara bürünen,

Köycüklerde, rencberlerin yurtlarında okunur:

(Biz Nasıl Şiir İsteriz?)

İtalyanca İsimler: Şiirlerde yalnızca bir İtalyanca isim kullanılmıştır. Bu isim şiirde şöyle geçmektedir:

Ey kardeşler!... Ses gelmiyor; âh kimseden ümid yok;

Kar yağıyor.. Fırtına var.. Yolu çı̆̆lar almıştır.

(Âh Analık Yâhud Zeyneb'in Duâsı)

Moğolca İsimler: Şiirlerde yalnızca bir Moğolca isim kullanılmıştır. Bu isim şöyle geçmektedir:

"Yiğit, arslan babamı pek garibsedim, özledim;

“Gün karardı; şimdiyedek onun yolun gözledim,

"Babacığım geliyor mu? Hiç yollarda gördün mü?

(Yetim Çocuk Yâhud Ahmed'in Kaygusu)

3. Yabancı ve Türkçe Kelime ya da Eklerle Oluşturulan Sözcükler:

Şiirlerde yirmi Türkçeleşmiş sözcük kullanılmıştır. Bu sözcüklerin bir kısmı yabancı köklere Türkçe eklerin gelmesiyle bir kısmı ise yabancı bir isim ile Türkçe bir yardımcı fiilin birleşmesi ile oluşmuş birleşik fiillerdir.

a.Yabancı Bir Kelime ve Türkçe Eklerle Oluşturulan Sözcükler:

Bu sözcükler yabancı bir kök ile Türkçe bir ekin birleşmesinden oluşmuş, isim, sıfat, zarf ve fiil görevinde kullanılmışlardır. Şiirlerde bu şekilde on sözcük bulunmaktadır. 
Örneğin: Yunanca “fidan”, Farsça “parça” sözcüğü ile Türkçe “+çık” eki, Arapça "garip” sözcüğü ile Türkçe “+se-” ekinin birleşmesiyle oluşan kelimeler Türkçenin bünyesine dahil edilmiş ve şiirlerde şu şekilde kullanılmıştır.

Yeşil, penbe gölgelere hasret çeken ırmağın

Eteğinde, birkaç kırık fidancığın yanında;

(Yetim Çocuk Yahud Ahmed'in Kaygusu)

Ey iyilik, ey dünyânın, insanlı̆̆ın ümidi!

Seni herkes bir parçacık dinleseydi, görseydi;

(Güzellik ve lyilik Karşısında)

Yiğit, arslan babamı pek garibsedim, özledim;

“Gün karardi; şimdiyedek onun yolun gözledim,

(Yetim Çocuk Yahud Ahmed'in Kaygusu)

b. Yabancı Bir İsim ile Türkçe Bir Yardımcı Fiilden Oluşan Birleşik Fiiller: Şiirlerde altı adet bu tür birleşik fiil kullanılmıştır. Fakat bunlardan üçü sıfat-fiil eki alarak sıfat görevinde kullanılmıştır. Örneğin: Şiirlerde Arapça "fedâ" ve "nur" sözcüğü ile Türkçe "etmek" ve "saçmak" yardımcı fiilleri ile oluşan bir birleşik fiil örneği görülmektedir.

Eski, yeni, tatl, yanı sesler ile dolusun!

Sevgi, gençlik, istek, sağlık fedâ olsun yolunda!..

(Şehid Yahud Osman'ın Yüreği)

Bu çerağdır: Obalara, konaklara nur saçan;

Bir köylünün işlerini târihlere basdıran

(Kur'an-1 Kerim)

\section{c. Türkçe-Arapça-Farsça kelime ve eklerin birleşmesi ile oluşan sözcükler}

Bunların dışında Farsça-Türkçe-Arapça, Arapça-Türkçe, Arapça-Farsça sözcük ve eklerin birleşmesi ile de oluşan bazı kelimeler şiirde kullanılmıştır. Bunlardan bazıları Farsça "her" ile Türkçe "bir" ve Arapça "şey” sözcüğünün, Arapça “insan” ile Türkçe "oğul” sözcüğünün, Arapça "bel” ile Farsça "ki” ekinin birleşmesiyle oluşan sözcükler şöyledir:

Bu Kitâb'tır :Akıllara herbir şeyi sorduran;

"Düşün sonra fi" diyen, doğru yollar gösteren.

(Kur'an-1 Kerim)

Senin için dolaşırım, tepeleri, belleri.

isterim ki bana herşey yol versin;

(Güzellik ve lyilik Karşısında)

Ey Allāh'ım! İnsan-oğlu başkasıçün kagusuz;

Önümdeki karlı dağlar, uçurumlar duygusuz; 
$50^{* \text { TAED }} 49$

Hüsna KOTAN

Beni koru; yetim hakkın kurda kuşa yedirtme!

(Âh Analık Yâhud Zeyneb'in Duâsı)

Yurdakul'un Türkçe Şiirler’i üzerinde yapılan inceleme neticesinde şu sonuçlara ulaşılmıştır:

Yurdakul, şiirlerinde ağırlıklı olarak Türkçe kelimeler kullanmış, bu sözcükler yanında az da olsa Arapça, Farsça, Yunanca, İtalyanca ve Moğolca kelimelere yer vermiştir.

Bu yer verdiği yabancı kelimelerin çoğunu da "hasret, gül, yabani, kulübe, firtına..." gibi günlük yaşamımızda yer edinen kelimelerden seçmiştir.

Yabancı kelimeler sadece isim soylu sözcüklerde kullanılmış, fiillerde bu kelimelere yer verilmemiştir. Türkçede vurgunun ve cümle kuruluşunun fiil üzerinde toplanması göz önünde bulundurulduğunda bu durum dikkate değerdir.

İncelediğimiz şiirlerdeki kelimelerin kullanım oranını aşağıdaki tabloda verilmiştir. Bu tabloya yabancı ve Türkçe kelime ya da eklerin birleşmesi ile oluşan sözcükler dâhil edilmemiştir. Bu sözcüklerin sayısı yirmi bir'dir. Bunlardan yalnızca ikisi Arapça ve Farsçanın birleşmesi ile oluşmuştur. Bunun dışındaki kelimelerin Türkçeleşmiş olduğunu düşünürsek, şiirlerde kullanılan Türkçe kelimelerin toplam sözcükler içersindeki sayısı üç yüz yetmiş yedi olmakta, oranı ise yüzde seksen iki'ye ulaşmaktadır.

\begin{tabular}{|c|c|c|c|c|c|c|}
\hline $\begin{array}{c}\text { Söz } \\
\text { cük Türleri }\end{array}$ & Türkçe & Arapça & Farsça & Yunanca & İtalyanca & Moğolca \\
\hline İsim & 120 & 34 & 21 & 9 & 1 & 1 \\
\hline Sıfat & 74 & 3 & 9 & - & - & - \\
\hline Zarf & 19 & 1 & 1 & - & - & - \\
\hline Zamir & 12 & 1 & 1 & - & - & - \\
\hline $\begin{array}{c}\text { Edat- } \\
\text { Bağlaç-Ünlem }\end{array}$ & 13 & - & 5 & - & - & - \\
\hline Fiil & 115 & - & - & - & - & - \\
\hline $\begin{array}{l}\text { Iki Görevde } \\
\text { Kullanılan } \\
\text { Sözcükler }\end{array}$ & 5 & 2 & - & - & - & - \\
\hline Toplam/ Oran & $\mathbf{3 5 8 / \% 7 8}$ & $\mathbf{4 1} / \% \mathbf{9}$ & $\mathbf{3 7} / \% \mathbf{8}$ & $\mathbf{9 / 1 . 9}$ & $1 / \% \mathbf{0 . 2}$ & $1 / \% 0.2$ \\
\hline
\end{tabular}

\begin{tabular}{|c|c|c|c|c|c|}
\hline \multirow{2}{*}{\multicolumn{2}{|c|}{$\begin{array}{l}\text { 1. Türkçe Kelimeler } \\
\text { İsimler }\end{array}$}} & \multirow{3}{*}{$\begin{array}{l}\text { Baba } \\
\text { Bağır } \\
\text { Baş }\end{array}$} & \multirow{3}{*}{$\begin{array}{l}\text { (T.) } \\
\text { (T.) } \\
\text { (T.) }\end{array}$} & \multirow{3}{*}{$\begin{array}{l}\text { Çiçek } \\
\text { Çocuk } \\
\text { Çok }\end{array}$} & \multirow{2}{*}{$\begin{array}{l}\text { (T.) } \\
\text { (T.) }\end{array}$} \\
\hline & & & & & \\
\hline Ad & (T.) & & & & (T.) \\
\hline $\mathrm{Ak}$ & (T.) & Başka & (T.) & Dağ & (T.) \\
\hline $\mathrm{Al}$ & (T.) & Bayrak & (T.) & Dayı & (T.) \\
\hline Alkış & (T.) & Bel & (T.) & Dış & (T.) \\
\hline Altun & (T.) & Ben & (T.) & Dil & (T.) \\
\hline Ana & (T.) & Bir & (T.) & Din & (T.) \\
\hline Ara & (T.) & Biri & (T.) & Doğru & (T.) \\
\hline Armagan & (T.) & $\mathrm{Biz}$ & (T.) & Düz & (T.) \\
\hline Ata & (T.) & Boyun & (T.) & El & (T.) \\
\hline Ay & (T.) & $\mathrm{Bu}$ & (T.) & El & (T.) \\
\hline Ayak & (T.) & Çamur & (T.) & Elma & (T.) \\
\hline
\end{tabular}




\begin{tabular}{|c|c|c|c|c|c|}
\hline En & (T.) & Nice & $(\mathrm{T})$. & Yüz & (T.) \\
\hline Erken & (T.) & $\mathrm{O}$ & (T.) & & \\
\hline Eski & (T.) & Oba & (T.) & \multicolumn{2}{|c|}{ İsimden Oluşan İsimler } \\
\hline Etek & (T.) & Ocak & (T.) & Benlik & (T.) \\
\hline Ev & (T.) & Oda & (T.) & Büyüklük & (T.) \\
\hline Gece & (T.) & Odun & (T.) & Çanlı & (T.) \\
\hline Genç & (T.) & Oğul & (T.) & Dikenli & (T.) \\
\hline Gök & (T.) & On & (T.) & Göğüsçük & (T.) \\
\hline Göl & (T.) & Orman & (T.) & Güzellik & (T.) \\
\hline Gölge & (T.) & Ot & (T.) & lssız & (T.) \\
\hline Gömlek & (T.) & Ova & (T.) & İyilik & (T.) \\
\hline Göz & (T.) & Öksüz & (T.) & Karanlık & (T.) \\
\hline Gün & (T.) & Ön & (T.) & Karlı & (T.) \\
\hline Güneş & (T.) & Öyle & (T.) & Kaygusuz & (T.) \\
\hline Güzel & (T.) & Öz & (T.) & Ocaklık & (T.) \\
\hline Hangi & (T.) & Pek & (T.) & Samanlık & (T.) \\
\hline Hep & (T.) & Sağlık & (T.) & Ululuk & (T.) \\
\hline Irmak & (T.) & Sen & (T.) & Tatlı & (T.) \\
\hline $\mathrm{i}_{c ̧}$ & (T.) & Ses & (T.) & Yavrucuk & (T.) \\
\hline iki & (T.) & Sirt & (T.) & Yoksul & (T.) \\
\hline il & (T.) & Siz & (T.) & Yolcu & (T.) \\
\hline ilk & (T.) & Son & (T.) & Yücelik & (T.) \\
\hline $\mathrm{i}_{s ̧}$ & (T.) & Sonra & (T.) & \multirow{2}{*}{\multicolumn{2}{|c|}{ Fiilden Oluşan İsimler }} \\
\hline $\mathrm{i}_{y i}^{3}$ & (T.) & Söğüd & (T.) & & \\
\hline Kan & (T.) & Su & (T.) & Açık & $(\mathrm{T})$ \\
\hline Kar & (T.) & Şimdi & (T.) & Ağlatan & (T.) \\
\hline Kara & (T.) & Şu & (T.) & Artıran & (T.) \\
\hline Kardaş/ kardeş & $(\mathrm{T})$. & Taş & (T.) & Asdıran & (T.) \\
\hline Kaygu & (T.) & Tepe & (T.) & Bağlatan & (T.) \\
\hline Keçi & (T.) & Ulu & (T.) & Basdıran & (T.) \\
\hline Kendi & (T.) & Ün & (T.) & Belirsiz & (T.) \\
\hline Kılıç & (T.) & Üzeri & (T.) & Besleyen & (T.) \\
\hline Kır & (T.) & Yalın & (T.) & Bilgi & (T.) \\
\hline$K_{1 z}$ & (T.) & Yalınız & (T.) & Boğaz & (T.) \\
\hline Kim & (T.) & Yan & (T.) & Bucak & (T.) \\
\hline Kimse & (T.) & Yaprak & (T.) & Bükük & (T.) \\
\hline Kişi & (T.) & Yaş & (T.) & Çeken & (T.) \\
\hline Koç & (T.) & Yavru & (T.) & Dönen & (T.) \\
\hline Koyun & (T.) & Yeni & (T.) & Dolu & (T.) \\
\hline Köle & (T.) & Yer & (T.) & Durak & (T.) \\
\hline Kötü & (T.) & Yeşil & (T.) & Ekin & $(\mathrm{T})$ \\
\hline Kucak & (T.) & Yiğit & (T.) & Geçmiş & (T.) \\
\hline Kul & (T.) & Yol & (T.) & Gösteren & (T) \\
\hline Kurt & (T.) & Yok & (T.) & lşık & (T.) \\
\hline Kuş & (T.) & Yurt & (T.) & İstek & (T.) \\
\hline Küçük & (T.) & Yuva & (T.) & Karaltı & (T.) \\
\hline Mutlu & (T.) & Yürek & (T.) & Kırık (T.) & \\
\hline Nerde & (T.) & Yüce & (T.) & Kızıl & (T.) \\
\hline & & & & Konak & (T.) \\
\hline
\end{tabular}




\begin{tabular}{|c|c|c|c|c|c|}
\hline \multicolumn{5}{|c|}{$52^{*}$ TAED 49} & Hüsna KOTAN \\
\hline Korkak & (T.) & Sessiz sessiz & (T.) & Dile- & (T.) \\
\hline Koru & (T.) & Sıkı sıkı & (T.) & Dinle- & $(\mathrm{T})$ \\
\hline Kurduran & (T.) & Üst baş & (T.) & Dokun- & (T.) \\
\hline Öğüt & (T.) & Yavaş yavaş & (T.) & Dol- & (Т.) \\
\hline Öğreten & (T.) & & & Don- & (Т.) \\
\hline Sesleyen & (T.) & \multicolumn{2}{|c|}{ Yansıma Sözcükler } & Dön- & (T.) \\
\hline Sergi & (T.) & Çarpıntı & (Yans.) & Dur- & (Т.) \\
\hline Sevgi & (T.) & Çı̆ & (Yans.) & Duy- & (T.) \\
\hline Sevinç & (T.) & Çıplak & (Yans) & Düşün- & (T.) \\
\hline Sezdiren & (T.) & Ninni & (Yans.) & Eyle- & (T.) \\
\hline Sızlatıcı & (T.) & Parlak & (Yans.) & Geç- & (Т.) \\
\hline Sönük & (T.) & & & Gel- & (T.) \\
\hline Soğuk & (T.) & & & Gid-/git- & (T.) \\
\hline Söz & (T.) & \multicolumn{2}{|c|}{ Bağlaçlar ve Edatlar } & Gir- & (T.) \\
\hline Tarla & (T.) & Çün & $(\mathrm{T})$. & Gör- & (T.) \\
\hline Toprak & (Т.) & De & (T.) & Göster- & (Т.) \\
\hline Uçurum & (T.) & Dek & (T.) & Güt- & (T.) \\
\hline Urgan & (T.) & için & (T.) & $\mathrm{i}_{c ̧-}$ & (T.) \\
\hline Uzak & (T.) & ile & (T.) & İnan- & (T.) \\
\hline Veren & (T.) & işte & (T.) & iste- & (T.) \\
\hline \multicolumn{2}{|c|}{ Yanan/ Yanık (T.) } & Haydin & hay+edin & Kal- & (Т.) \\
\hline Yapı & $(\mathrm{T})$. & $\mathrm{Ne}$ & $(\mathrm{T})$. & Kalk- & (T.) \\
\hline Yara & (T.) & Yalınız & (T.) & Karar- & (T.) \\
\hline Yaradan & (T.) & Yine & (Т.) & Kat- & (T.) \\
\hline Yatak & (T.) & Ünlemler & & Kes- & (T.) \\
\hline Yayla & (T) & $\hat{A} \mathrm{~h}$ & nlem) & Koru- & (T.) \\
\hline \multirow[t]{2}{*}{ Yaylım } & (T.) & Ey & nlem) & Koş- & (T.) \\
\hline & & Oh & nlem) & Koy- & (T.) \\
\hline \multicolumn{2}{|c|}{ Özel İsimler } & & & Okşa- & (T.) \\
\hline Türk & (T.) & Fiiller & & Ol- & (T.) \\
\hline Tanrı & (T.) & Acl- & (T.) & Öğ- & (T.) \\
\hline \multicolumn{2}{|c|}{ Karadeniz Boğazı (T.) } & Aç- & (T.) & Öt- & (T.) \\
\hline Köroğlu & (T.) & Ağla- & (T.) & Özle- & (T.) \\
\hline \multirow[t]{2}{*}{ Kizılırmak } & (T.) & $A k-$ & (T.) & Saç- & (T.) \\
\hline & & Al- & (T.) & Sakla- & (T.) \\
\hline \multicolumn{2}{|c|}{ Birleşik İsimler } & An- & (T.) & Sakın- & (T.) \\
\hline Birgün & (T.) & At- & (T.) & Sal- & (T.) \\
\hline Birkaç & (T.) & Ayır- & (T.) & Say- & (T.) \\
\hline Böyle & (T.) & Bak- & (T.) & Seç- & (T.) \\
\hline Bugün & (T.) & Bekle- & (T.) & Serp- & (T.) \\
\hline Gece-kuşu & (T.) & Bil- & (T.) & Sev- & (T.) \\
\hline Gökyüzü & (T.) & Bit - & (T.) & Sok- & (T.) \\
\hline Gözyaşı & (T) & Bul- & (T.) & Sor- & (T.) \\
\hline \multirow[t]{3}{*}{ Yeryüzü } & (T.) & Büyü- & (T.) & Söyle- & (T.) \\
\hline & & Çalış- & (T.) & Sus- & (T.) \\
\hline & & Çarp- & (T.) & Taş- & (T.) \\
\hline ilkilemeler & & Çık- & (T.) & Tut- & (T.) \\
\hline Etek etek & (T.) & De- & (T.) & Tüt- & (T.) \\
\hline Eski püskü & (T.) & Dik- & $(\mathrm{T})$ & Var- & (T.) \\
\hline
\end{tabular}




\begin{tabular}{|c|c|c|c|c|c|}
\hline Ver- & (T.) & \multirow{2}{*}{\multicolumn{2}{|c|}{$\begin{array}{l}\text { Arapça Kelimeler } \\
\text { İsimler }\end{array}$}} & Ateş & (Far.) \\
\hline Yağ- & (T.) & & & Bağ & (Far.) \\
\hline Yak- & (T.) & Akıl & (Ar.) & Bahçe & (Far.) \\
\hline Yaklaş- & (T.) & Beyaz & (Ar.) & Bahtiyâr & (Far.) \\
\hline Yan- & (Т.) & Devlet & (Ar.) & Cenk & (Far.) \\
\hline Yap- & (T.) & Du'a & (Ar.) & Can & (Far.) \\
\hline \multirow[t]{2}{*}{ Yarış- } & (Т.) & Dünyâ & (Ar.) & Çerağ & (Far.) \\
\hline & & Ecdâd & (Ar.) & Çirkin & (Far.) \\
\hline \multicolumn{2}{|c|}{ İsimden Türemiş Fiiller } & Evlâd & (Ar.) & Çoban & (Far.) \\
\hline Gizle- & (T.) & Fenâ & (Ar.) & Coşkun & (Far) \\
\hline Gözle- & (T.) & Gayet & (Ar.) & Dere & (Far.) \\
\hline Isit- & (T.) & Haber & (Ar.) & Dost & (Far.) \\
\hline \multirow[t]{2}{*}{ Yaşa- } & (T.) & Hak & (Ar.) & Düşman & (Far.) \\
\hline & & Heykel & (Ar.) & Gerden & (Far.) \\
\hline \multicolumn{2}{|c|}{ Fiilden Türemiş Fiiller } & Hisar & (Ar.) & Gonca & (Far.) \\
\hline Asıl- & (T.) & Insan & (Ar.) & Gül & (Far.) \\
\hline Asdır- & (T.) & Kabir & (Ar.) & Harman & (Far.) \\
\hline Bellet- & (Т.) & $\mathrm{Kal}^{\mathrm{e}} \mathrm{a}$ & (Ar.) & Herkes & (Far.) \\
\hline Bürün- & (T.) & Kevkeb & $\begin{array}{l}\text { (Ar.) } \\
\text { (Ar.) }\end{array}$ & Hiç & (Far.) \\
\hline Çaldırt- & (T.) & Kitâb / kitap & $\begin{array}{l}\text { (Ar.) } \\
\text { (Ar.) }\end{array}$ & Kement & (Far.) \\
\hline Çarpış- & (Т.) & Kule & (Ar.) & Köy & (Far.) \\
\hline Deril- & (Т.) & Mâvi & (Ar.) & Penbe & (Far.) \\
\hline Dolaş- & (Т.) & Mescid & (Ar.) & Rencber & (Far.) \\
\hline Düzle- & (Т.) & Mezar & (Ar.) & Ser & (Far.) \\
\hline Getirt- & (T.) & Millet & (Ar.) & Sine & (Far.) \\
\hline Kaldırt- & (T.) & Nesil & (Ar.) & Tâze & (Far.) \\
\hline Kazdır- & (T.) & Nur & (Ar.) & Ten & (Far.) \\
\hline Konul- & (Т.) & Sur & (Ar.) & Ümid & (Far.) \\
\hline Kopar- & (Т.) & Sâhid & (Ar) & Viran & (Far.) \\
\hline Kurdur- & (T.) & Sehid & (Ar.) & Yabanî & (Far.) \\
\hline Okun- & (Т.) & Sey & (Ar.) & Yar & (Far.) \\
\hline Saldırt- & (T.) & Siir & (Ar.) & \multirow{2}{*}{\multicolumn{2}{|c|}{ Bağlaçlar ve Edatlar }} \\
\hline Sevin- & (T.) & $\begin{array}{l}\text { ŞIIr } \\
\text { Târih }\end{array}$ & $\begin{array}{l}\text { (Ar.) } \\
\text { (Ar.) }\end{array}$ & & \\
\hline Urdur- & (T.) & Vakit & (Ar.) & Eğer & (Far.) \\
\hline Yazdır - & (T.) & Vatan & (Ar.) & Her & (Far.) \\
\hline Yazıl- & (T.) & Yetim & (Ar.) & $\mathrm{Ki}$ & (Far.) \\
\hline \multirow[t]{2}{*}{ Yedirt- } & (T.) & Zelzele & (Ar.) & $\mathrm{Ya}$ & (Far.) \\
\hline & & & & Yahut & (Far.) \\
\hline Birleşik Fiiller & & Özel İsimler & & \multirow{3}{*}{\multicolumn{2}{|c|}{$\begin{array}{l}\text { Yunanca Kelimeler } \\
\text { İsimler }\end{array}$}} \\
\hline Bıçak bile- & (T.) & Ahmed & (Ar.) & & \\
\hline Ekin biç- & (T.) & Fâtih & (Ar.) & & \\
\hline \multicolumn{2}{|c|}{ Gözlerini yola dik- (T.) } & \multicolumn{2}{|c|}{ Kur'an-1 Kerim(Ar.) } & Cins & (Yun.) \\
\hline Gözyaşı sil- & (T.) & Osman & (Ar.) & Demet & (Yun.) \\
\hline Kaygu çök- & (T.) & Muhammed & $\begin{array}{l}\text { (Ar.) } \\
\text { (Ar.) }\end{array}$ & Kulübe & (Yun.) \\
\hline Odun kes- & (T.) & $\begin{array}{l}\text { Munammed } \\
\text { Zeynep }\end{array}$ & $\begin{array}{l}\text { (Ar.) } \\
\text { (Ar.) }\end{array}$ & Sınır & (Yun.) \\
\hline Yol aç- & (T.) & & & Sira & (Yun.) \\
\hline Yol ver- & (T.) & Farsça Kelim & & & \\
\hline Yolunu gözle- & (T.) & İsimler & & $\begin{array}{l}\text { Özel İsim } \\
\text { Anadolu }\end{array}$ & (Yun.) \\
\hline
\end{tabular}




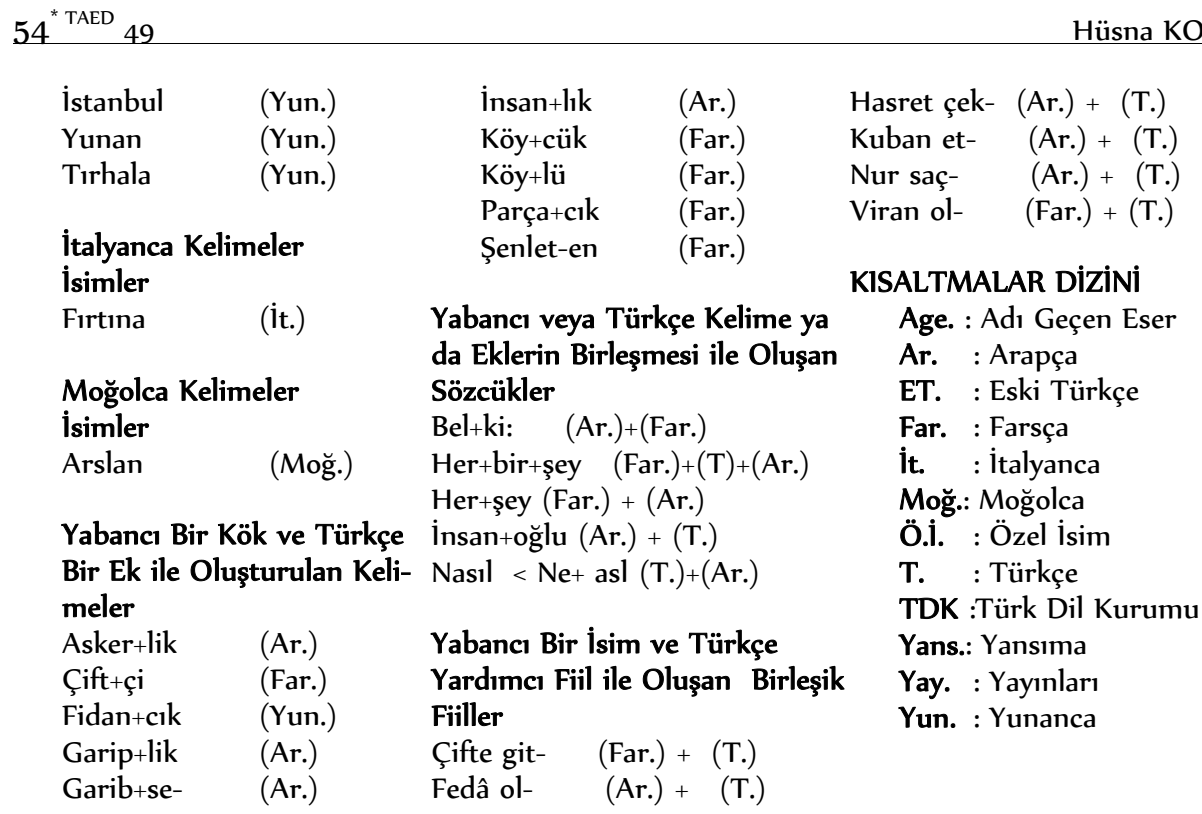

\section{KAYNAKÇA}

ÇAĞBAYIR, Yaşar. Ötüken Türkçe Sözlük. İstanbul: Ötüken Yayınları, 2007.

DEVELLiOĞLU, Ferit. Osmanlıca- Türkçe Ansiklopedik Lûgat. Ankara: Aydın Kitabevi, 2002.

ENGiNüN, İnci. Yeni Türk Edebiyatı Tanzimat'tan Cumhuriyet'e (1839-1923). İstanbul: Dergâh Yayınları, 2006.

EREN, Hasan. Türk Dilinin Etimolojik Sözlüğü. Ankara: Bizim Büro Basımevi, 1999.

GÜLENSOY, Tuncer. Türkiye Türkçesindeki Türkçe Sözcüklerin Köken Bilgisi Sözlüğü. Ankara: Türk Tarih Kurumu Yayınları, 2007.

KANAR, Mehmet. Farsça-Türkçe Sözlük. ìstanbul: Deniz Kitabevi, 2000.

LEVEND, Agâh Sırrı. Türk Dilinde Gelişme ve Sadeleşme Safhaları. Ankara Türk Tarih Kurumu Basımevi, 1949.

OĞUZKAN, A. Ferhan. Mehmet Emin Yurdakul Hayatı Sanatı Eserleri, ìstanbul: Varlık Yayınevi, 1953.

ÖKSüZ, Yusuf Ziya. Türkçenin Sadeleşme Tarihi Genç Kalemler ve Yeni Lisan Hareketi. Ankara: Türk Tarih Kurumu Yayınları, 2004.

NiŞANYAN, Sevan. Sözlerin Soyağacı Çağdaş Türkçenin Etimolojik Sözlüğü, İstanbul: Adam Yayınları, 2010.

TANSEL, Fevziye Abdullah. Mehmet Emin Yurdakul'un Eserleri- I Şiirler. Ankara: Türk Tarih Kurumu Yayınlarından Seri: Il- Sayı: 24, TTK. Basımevi, 1969.

Türk Dil Kurumu. Derleme Sözlügü. Ankara: 1993.

Türkçe Sözlük. Ankara, 2005.

YAZICl, Yüksel. Mehmet Emin Yurdakul. İstanbul: Toker Yayınları, 1974.

ZÜLFiKAR, Hamza. Türkçede Ses Yansımalı Kelimeler İnceleme-Sözlük. Ankara: Türk Tarih Kurumu Yayınları, 1995. 